\title{
The Relative Impact of Market, Internal, and Overall Job Values on Pay Competitiveness
}

\author{
William J. Liccione, Ph.D. \\ President \\ Compensation Planning \& Analytics \\ 200 South Brentwood Blvd., Suite 16C \\ Saint Louis, Missouri 63105, USA
}

Received: Dec. 20, 2018 Accepted: Jan. 14, 2019 Online published: Jan. 29, 2019

doi:10.5296/ijhrs.v9i1.13821 URL: https://doi.org/10.5296/ijhrs.v9i1.13821

\begin{abstract}
As a practical imperative, organizations must be able to attract, retain, and motivate qualified employees to remain going concerns. Those that adopt a market-based strategy that focuses on paying market-competitive wages may effectively attract and retain employees and, depending upon their compensation planning process, encourage employees' belief in the distributive justice of their organizations' pay decisions. Alternatively, organizations that adopt an internal equity strategy that focuses on pay decisions that reflect the internal value of employees' jobs to their organization may effectively retain employees and, depending upon the process used to determine internal job values, encourage employees' belief in the equity or procedural justice of that process. Compared to these strategies, organizations that rely on measures of overall job value are focusing on neither the market values, nor their internal values of jobs, alone. Instead, they are focusing on the jobs' overall values, or their amended market values given the influence of the jobs' internal values to the organization. As such, overall job value impacts, at once, the organizations' need to attract, retain and motivate employees.

This article evaluates the relative impact of market, internal, and overall job value on the competitiveness of 88 employees' pay in 41 jobs in a nonprofit organization in the US health care sector. The organization's pay decisions were made prior to this study and without benefit of a formal salary management plan. Hence, this study represents a retrospective analysis of the relative impact of jobs' market, internal, and overall value on pay competitiveness.
\end{abstract}

Keywords: job evaluation, market value, internal job value, overall job value, pay 
competitiveness

\section{Variables}

Measurable definitions of the following variables were developed in conjunction with the development of the organization's first salary management plan. These variables then provided a framework for retrospectively evaluating the impact of jobs' market, internal, and overall values on pay decisions the organization made for 88 of its employees in 41 jobs prior to beginning its plan development.

\subsection{Job Value}

The following three measures of job value reflect three different strategies for making pay decisions and were used as the independent variables in this analysis. The method used to develop each variable is described below.

\subsection{Market Value}

Since Adams $(1963,1965)$ first discussed the significance of the perceived equity/inequity of distributed rewards in social exchanges, both the evolution of equity theory and research on distributive justice indicate that, when organizations use a clear, identifiable standard for adjusting pay, (e.g., labor market movement adjusted for performance differences) employees are more satisfied with the fairness of their pay adjustments than when less objective standards are used (Tyler, Rasinski, \& McGraw, 1985). From this perspective, the fully competitive market values of the organization's jobs provide a foundation for attracting employees, and encouraging their retention based on the perceived equity of the organization's pay decisions. An organization that adopts this market-based strategy ipso facto places a premium on determining the current fully competitive value of employees' jobs and using it as a basis for ongoing pay decisions.

In this study, the current $50^{\text {th }}$ percentile market values of jobs were used to operationally define the jobs' fully competitive market rates in the national, regional, or local geographic markets in which the organization competed for qualified job candidates, and were calculated using published pay data. Decisions regarding the jobs' market rates reflected the approved, written descriptions of their purpose and essential duties. Multiple sources of published pay data were used to determine each job's market rate, and the rate was made current as of an agreed upon compensation planning date.

\subsection{Internal Value}

Unlike a market-based pay strategy that encourages employees' evaluations of their own pay adjustments, an internal equity strategy focuses employees' attention on the procedures, per se, used to evaluate the internal values of their jobs, as well as the internal values of other jobs they compare theirs to. When employees believe these procedures are just, it encourages their belief in, not only the fairness of their organizations' procedures, in general, but also their instrumentality in recognizing employee performance (Stecher, \& Rosse, 2007). From this perspective, a belief in the procedural justice of the organization's method of determining internal job value becomes an important source of employee motivation. An organization that 
adopts this internal value strategy would be expected to place a premium on the development of an organization-specific method of measuring internal value and rely heavily upon factors that discriminate among jobs in terms of their internal value to determine pay adjustments.

In this study a tailored, organization-specific measure of internal value was developed that accurately reflected the way this organization differentiated jobs in terms of their internal value. Essentially, factors were developed that applied to all of the organization's jobs and allowed it to define the internal value of each job in terms of points. The methodology used to develop this tailored point factor plan is described, in detail, by Liccione (2014). Following is a summary of the 6-step process used.

Step 1: Factor Identification. The organization was first asked to identify a number of key employees who knew its work culture well enough to offer an informed opinion regarding the factors, or dimensions of jobs, the organization actually used to separate jobs in terms of their internal value (e.g., impact on the quality of patient care, depth of expertise required for completely satisfactory performance, etc.). A confidential, in-depth interview was then conducted with each key employee to determine his or her identified factors.

Step 2. Factor Definitions. After the key employees were interviewed, a written definition was developed for each internal value factor mentioned. When developing the definitions, each identified factor scale used by the organization to differentiate jobs' internal values was defined using at least an ordinal level of measurement appropriate to the organization. Table 1 shows an example of an appropriate ordinal scale for describing the factor scale, Depth of Expertise Required for Completely Satisfactory Performance.

Table 1. Sample Internal Value Factor - Depth of Expertise Required for Completely Satisfactory Performance $($ Weight $=200)$

\begin{tabular}{c|l|l}
\hline Score & \multicolumn{1}{|c|}{ Level } & \multicolumn{1}{c}{ Definition } \\
\hline 1 & $\begin{array}{l}\text { Basic } \\
\text { Knowledge \& } \\
\text { Skill }\end{array}$ & $\begin{array}{l}\text { Completely satisfactory performance in this job requires basic knowledge requires } \\
\text { basic knowledge and skill. Examples include a knowledge of basic math (e.g., } \\
\text { addition, subtraction, multiplication, division) and basic rules of grammar, etc.) } \\
\text { and/or ability to operate basic equipment (e.g., fax machine, copier, person computer, } \\
\text { desk computer, etc.) }\end{array}$ \\
\hline 3 & $\begin{array}{l}\text { Simited } \\
\text { Specialization }\end{array}$ & $\begin{array}{l}\text { Completely satisfactory performance in this job requires the application of basic } \\
\text { job-specific knowledge and skills which are applied within clearly defined } \\
\text { parameters using standard operating procedures (e.g., manipulating data within an } \\
\text { already-developed spreadsheet, administering benefit enrollment procedures, etc.) }\end{array}$ \\
\hline 5 & Specialization & $\begin{array}{l}\text { Completely satisfactory performance requires the learning and application of } \\
\text { specialized knowledge and skills that are related to one or more formally recognized } \\
\text { functions within the organization (e.g., sales, marketing, human resources, } \\
\text { information systems, etc.). Examples include responsibility for benefit plan } \\
\text { administration, the delivery of complex training programs, etc. }\end{array}$ \\
\hline
\end{tabular}


Step 3: Factor Scoring Schemas. After developing written definitions of the internal value factors, numeric values were attached to the different levels of each scale included in a factor. The differences in these values were not necessarily equal, but instead reflected the significance of the different scale levels to the organization. For example, in the sample internal value factor shown in Table 1, the first level of the factor, Basic Knowledge \& Skill, is assigned a numeric value of 1; the second level of the factor, Limited Specialization, is assigned a numeric value of 3 , and the third level, Specialization, is assigned a numeric value of 5 .

Step 4: Factor Points. After the factor scoring schemas were developed, the organization's job evaluation committee compared the content of each job against the levels of each scale in each factor, and assigned the job the number values, or points, that best described its content. For example, if the committee decided that the depth of expertise required for completely satisfactory performance in a job was "limited specialization", as defined in Table 1, it would assign the job a 3 for that factor.

Step 5: Factor Weights. Multiple regression analyses were conducted to evaluate the strength of the relationship between the scores assigned jobs on each factor and the jobs' $50^{\text {th }}$ percentile market rates. Factor weights were then calculated based upon the strength of that relationship: the stronger the relationship between jobs' scores, or point totals, on a factor and their market values, the heavier the factor's weight, calculated on a base of 1,000 .

Step 6: Weighted Factor Points. To determine a job's weighted point score on a factor, the points assigned the job were divided by the maximum points possible, and the quotient was multiplied by the factor's weight. Using the example in step 4 above, if the job evaluation committee assigned a job a 3 on the internal value factor shown in Table 1, the maximum score on that factor is 5, and the factor's weight is 200 , then the job would be credited with 120 weighted factor points:

Weighted Factor Points $=($ Point Score/ Maximum Possible Points $)$ Factor Weight

$$
=(3 / 5)(200)=(60 \%)(200)=120
$$

A job's total weighted factor points is the sum of the weighted points assigned to the job on each factor in the plan.

\subsection{Overall Value}

While a market-based pay strategy emphasizes the market value of jobs and an internal equity strategy emphasizes the internal values of jobs to the organization, an overall value strategy emphasizes the impact of internal values on market values. In other words, it emphasizes the market values of jobs given their internal values to the organization. Hence, an organization that considers a job sufficiently valuable may decide to pay its incumbent(s) a premium over its fully competitive $50^{\text {th }}$ percentile market rate, while an organization that does not consider a job as valuable as it once was, let's say, may decide to allow the competitiveness of its incumbent(s) pay to slip below its $50^{\text {th }}$ percentile market rate. An organization that adopts this overall value strategy would be expected to evaluate its jobs more holistically than it would 


\section{Macrothink}

using either of the other strategies discussed here

In this study, a job's overall value is defined by the trendline resulting from a linear regression analysis of the jobs' $50^{\text {th }}$ percentile market values and internal values to the organization. The resulting trendline formula for the 88 jobs in this analysis is:

$$
\text { Overall Job Value }=-\$ 5985.5427+\$ 136.806763 \text { (Total Weighted Points) }
$$

For example, a job assigned a total of 500 weighted points on all of the factors included in the organization's point factor plan would have an overall value of $\$ 61,021$ :

$$
\begin{aligned}
\text { Overall Job Value } & =-\$ 4018.562+[\$ 130.08(\text { Total Weighted Points) }] \\
& =-\$ 4018.562+[\$ 130.08(500)] \\
& =-\$ 4018.562+65,040 \\
& =\$ 61,021.44 \sim \$ 61,021
\end{aligned}
$$

Figure 1 below shows the Overall Value trendline resulting from the 41 jobs in this analysis.

Since this regression analysis predicts the market values of jobs given their internal values to the organization, the trendline is similar to what Newman, Gerhart, \& Milkovich (2017), and Martocchio (2011) refer to as a market pay line, and the overall values of jobs are equivalent to the market pay line's predicted market values. However, it is important to note that these predicted market values are seldom the same as the jobs' actual market values (Liccione, 2014). While, statistically, the differences reflect the regression model's prediction error, from a compensation perspective they also reflect the degree to which the jobs' internal values to the organization alter their labor market values. The concept of overall job value underscores this fact, (Dielman, 2005).

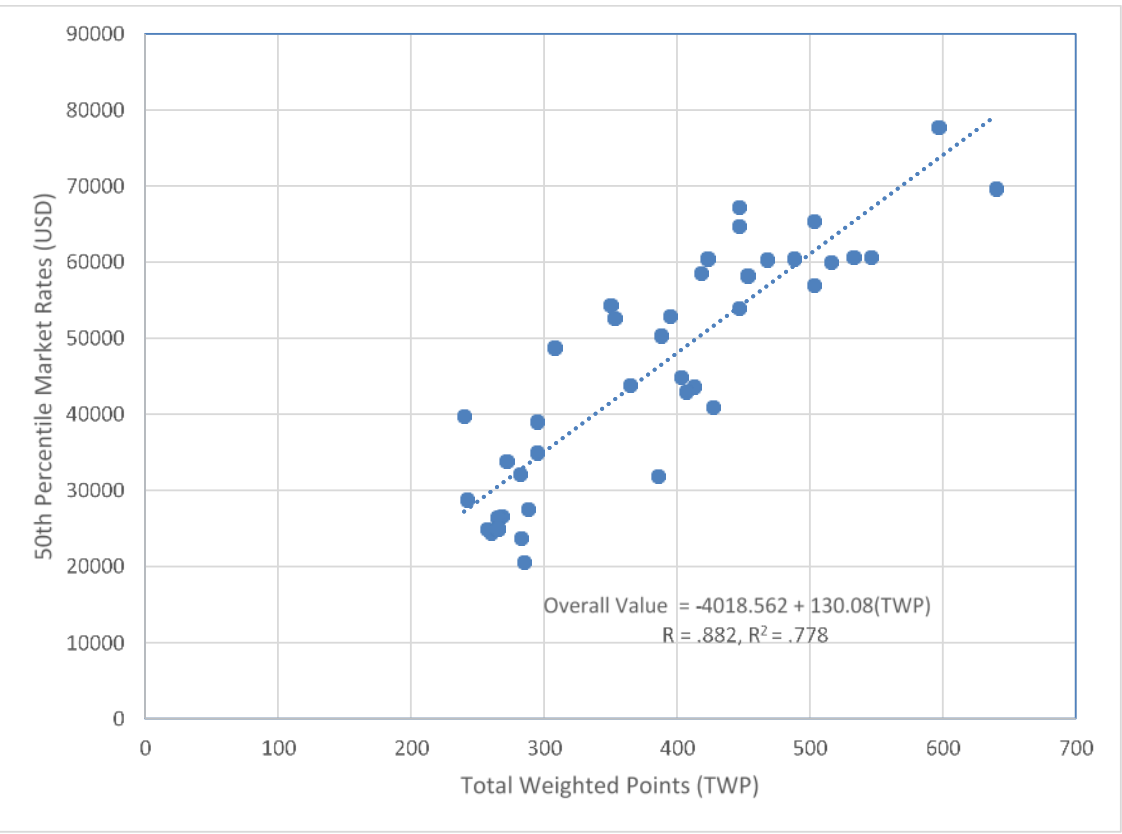

Figure 1. Overall Value Trendline 
1.5: Pay Competitiveness. Pay competitiveness was selected as the dependent variable in this study for two reasons. First, it is a key factor in the organization's ability to attract and retain employees. And second, because it reflects decisions made, not only when employees are first hired, but also over their tenure with the organization, reflecting their pay adjustments, promotions, demotions, etc. To calculate employees' pay competitiveness, data were collected on their current pay prior to the of the development of the organization's salary management. Then, their pay was divided by the $50^{\text {th }}$ percentile market values of their jobs:

\section{Pay Competitiveness $=$ Current Base $/ 50^{\text {th }}$ Percentile Market Value of the Job}

Using this formula, a quotient equal to less than 1 indicated an incumbent's current base was less than the job's current, fully competitive, 50th percentile market value, and a quotient greater than 1 indicated an incumbent's current base was greater than that market value. Generally, the larger the quotient the more competitive the incumbents' base pay was defined as being. Table 2 below shows the resulting database used in the current analysis.

\section{Analysis}

\subsection{Data Screening}

Before evaluating the impact of a market-based, internal equity, and overall value strategies on employee's pay competitiveness, the data were evaluated to ensure that cases with missing values, outliers, and/or variables with multicollinearity would not impact the results of the analysis

The data set used in this analysis included information on 89 employees in 42 jobs. During the regression analysis conducted to determine the overall value trendline discussed above, the total weighted internal values of jobs were converted to standard scores, and an outlier was defined as a standard score equal to or greater than 3 standard deviations. Using this operational definition, one job was defined as an outlier, and both the job and the single incumbent in the job were eliminated from the database. As Table 2 shows, the remaining 88 employees in 41 jobs represent complete sets of data, without missing values.

Table 2. Database

\begin{tabular}{|c|c|c|c|c|c|c|c|c|c|c|c|c|c|}
\hline $\begin{array}{c}\text { CP\&A } \\
\text { Emp. } \\
\text { Number }\end{array}$ & $\begin{array}{c}\text { 50th \%ile } \\
\text { Market } \\
\text { Rate }^{1}\end{array}$ & P.C. $^{2}$ & $\begin{array}{l}\text { Total } \\
\text { Points }\end{array}$ & $\begin{array}{c}\text { Total } \\
\text { Wt. } \\
\text { Points }\end{array}$ & $\begin{array}{l}\text { Overall } \\
\text { Value }\end{array}$ & $\begin{array}{l}\text { Overall } \\
\text { Minus } \\
\text { Market }\end{array}$ & $\begin{array}{c}\text { CP\&A } \\
\text { Emp. } \\
\text { Number }\end{array}$ & $\begin{array}{c}\text { 50th \%ile } \\
\text { Market } \\
\text { Rate }^{1}\end{array}$ & P.C. ${ }^{2}$ & $\begin{array}{l}\text { Total } \\
\text { Points }\end{array}$ & $\begin{array}{l}\text { Total } \\
\text { Wt. } \\
\text { Points }\end{array}$ & $\begin{array}{l}\text { Overall } \\
\text { Value }\end{array}$ & $\begin{array}{l}\text { Overall } \\
\text { Minus } \\
\text { Market }\end{array}$ \\
\hline 72 & $\$ 39,738$ & 0.86 & 36 & 240 & $\$ 27,201$ & $-\$ 12,538$ & 177 & $\$ 50,373$ & 1.00 & 56 & 388 & $\$ 46,452$ & $-\$ 3,921$ \\
\hline 28 & $\$ 24,467$ & 1.00 & 40 & 260 & $\$ 29,802$ & $\$ 5,335$ & 264 & $\$ 44,881$ & 1.05 & 68 & 403 & $\$ 48,404$ & $\$ 3,523$ \\
\hline 33 & $\$ 24,467$ & 1.00 & 40 & 260 & $\$ 29,802$ & $\$ 5,335$ & 60 & $\$ 60,023$ & 1.02 & 80 & 516 & $\$ 63,103$ & $\$ 3,079$ \\
\hline 70 & $\$ 24,467$ & 1.02 & 40 & 260 & $\$ 29,802$ & $\$ 5,335$ & 23 & $\$ 58,536$ & 0.94 & 63 & 418 & $\$ 50,355$ & $-\$ 8,181$ \\
\hline 112 & $\$ 24,467$ & 1.08 & 40 & 260 & $\$ 29,802$ & $\$ 5,335$ & 212 & $\$ 52,701$ & 0.69 & 49 & 353 & $\$ 41,900$ & $-\$ 10,801$ \\
\hline 138 & $\$ 24,467$ & 1.06 & 40 & 260 & $\$ 29,802$ & $\$ 5,335$ & 81 & $\$ 52,908$ & 1.07 & 55 & 395 & $\$ 47,363$ & $-\$ 5,545$ \\
\hline 146 & $\$ 24,467$ & 1.16 & 40 & 260 & $\$ 29,802$ & $\$ 5,335$ & 154 & $\$ 52,908$ & 1.01 & 55 & 395 & $\$ 47,363$ & $-\$ 5,545$ \\
\hline 155 & $\$ 24,467$ & 1.08 & 40 & 260 & $\$ 29,802$ & $\$ 5,335$ & 196 & $\$ 52,908$ & 1.01 & 55 & 395 & $\$ 47,363$ & $-\$ 5,545$ \\
\hline 232 & $\$ 24,467$ & 1.01 & 40 & 260 & $\$ 29,802$ & $\$ 5,335$ & 319 & $\$ 52,908$ & 0.94 & 55 & 395 & $\$ 47,363$ & $-\$ 5,545$ \\
\hline
\end{tabular}




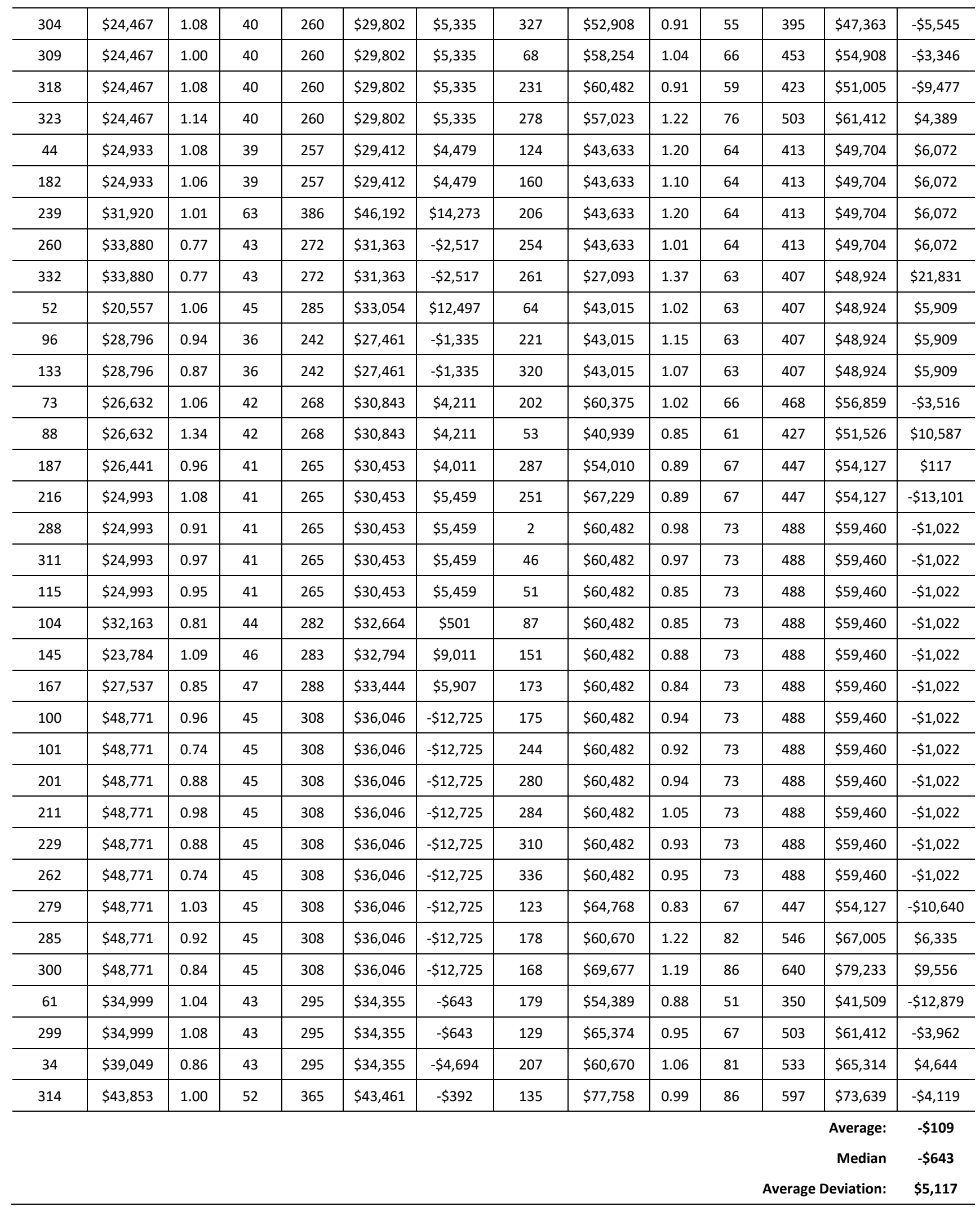

${ }^{1} \mathbf{5 0}^{\text {th }}$ Percentile Market Rate indicates the current $50^{\text {th }}$ percentile market value of the employee's job in the labor market in which the organization competed for qualified employees. ${ }^{2}$ P.C. indicates an individual employee's pay competitiveness. 


\section{Macrothink}

International Journal of Human Resource Studies

ISSN 2162-3058

2019, Vol. 9, No. 1

The data set used in this analysis included information on 89 employees in 42 jobs. During the regression analysis conducted to determine the overall value trendline discussed above, the total weighted internal values of jobs were converted to standard scores, and an outlier was defined as a standard score equal to or greater than 3 standard deviations. Using this operational definition, one job was defined as an outlier, and both the job and the single incumbent in the job were eliminated from the database. As Table 1 shows, the remaining 88 employees in 41 jobs represent complete sets of data, without missing values.

To evaluate the multicollinearity among the market value, internal value, and overall values of jobs (i.e., the predictor variable in this analysis) collinearity statistics were used to calculate the variance inflation factor (VIF) associated with each variable. The results of the analysis indicated that, although multicollinearity existed, the values of VIF were not large enough to suggest it interfered with the regression model estimates of the regression coefficients. However, the values were large enough to suggest the possibility of some influence on the values of the coefficient of determination $\left(\mathrm{R}^{2}\right)$ shown below. Consequently, the values of $\mathrm{R}^{2}$ should be interpreted with some caution (Kutner, Nachtsheim, \& Neter, 2004).

\subsection{Operational Definitions}

\subsubsection{Market Value}

The market value of a job was defined as its current $50^{\text {th }}$ percentile market value in the labor market in which the organization competes for qualified job candidates.

\subsubsection{Internal Value}

The internal value of a job to the organization was defined as the sum of its unweighted points on all factors in the plan. Even though the job's weighted point total was calculated and used to determine its overall value, or predicted market value, its total unweighted points were considered a more direct measure of the job's value to the organization.

\subsubsection{Overall Value}

A job's overall value was defined as the $50^{\text {th }}$ percentile market rate given its total weighted internal value points and was calculated using the following formula for the overall value trendline:

$$
\text { Overall Value }=-\$ 4018.562+[\$ 130.08(\text { Total Weighted Points })]
$$

\subsubsection{Pay Competitiveness}

The competitiveness of an employee's pay was determined by pay data collected prior to beginning the development of the organization's salary management plan, and was calculated using the following formula:

Pay Competitiveness $=$ Current Base $/ 50^{\text {th }}$ Percentile Market Value of the Job 


\section{Results}

\subsection{Significance of Predictions}

A partial F test (Gravetter, \& Wallnau, 2013) was conducted to evaluate the statistical significance of predictions of employees' pay competitiveness based upon decisions made prior to the development of the measures of market job value, internal job value and overall job value discussed here. Using this method, three regression analyses were conducted. In all three, pay competitiveness was the dependent, predicted, variable. However, in the first, partial, analysis (i.e. Model 1), only the market values of jobs were used as a predictor variable. In the second, partial, analysis (i.e. Model 2), both the market values and internal value of jobs were used as predictor variables; and in the third, full, analysis (i.e., Model 3), the market values, internal values and overall values of jobs were included as predictor variables. The marginal differences in the statistical significance of the models' predictions were evaluated by comparing the differences between each Model's F statistics. The results of the partial $\mathrm{F}$ test are included in Table 3.

They indicate that, when only the market values of jobs are included as a predictor in Model 1 , the statistical significance of the model's F statistic is .023. In hypothesis testing terms, if an analyst tested the null hypothesis that the market rates of jobs do not impact the organization's decisions regarding pay competitiveness and then decided to reject that null hypothesis based upon these results, the probability of the analysist being wrong (and making a Type 1 error) would be .023 , or $2.3 \%$. Essentially, the results indicate that the market rates of employees' jobs have a statistically significant impact on the organization's decisions regarding the competitiveness of their pay.

Table 3. Partial F Test

\begin{tabular}{c|c|c|c|c|c|c|c}
\hline Model & $\begin{array}{c}\text { Predictor } \\
\text { Variable(s) }\end{array}$ & $\mathrm{R}$ & $\mathrm{R}^{2}$ & Adjusted R & $\mathrm{R}^{2}$ Change & F Change $^{2}$ & $\begin{array}{c}\text { Significance } \\
\text { of F Change }\end{array}$ \\
\hline Partial Model 1 & Market Value & 0.242 & 0.059 & 0.048 & 0.059 & 5.362 & 0.023 \\
\hline Partial Model 2 & $\begin{array}{c}\text { Market Value } \\
\text { Internal Value }\end{array}$ & 0.582 & 0.338 & 0.323 & 0.280 & 35.908 & $>.0005$ \\
\hline Full Model 3 & $\begin{array}{c}\text { Market Value } \\
\text { Internal Value } \\
\text { Overall Value }\end{array}$ & 0.627 & 0.394 & 0.372 & 0.055 & 7.668 & 0.007 \\
\hline
\end{tabular}

${ }^{1}$ The value of R2 Change for Partial Model 1 is the value of the Correlation Coefficient, R2, that results from a simple regression analysis using the model's single predictor variable, market value.

${ }^{2}$ The value of F Change for Partial Model 1 is the value of the F statistic that results from a simple regression analysis using the model's single predictor variable, market value.

${ }^{3}$ The value of the Significance of F Change for Partial Model 1 is the significance of the value of F statistic that results from a simple regression analysis using the model's single predictor variable, market value. 
When both the market values and internal values of employees' jobs are included as predictors of their pay competitiveness in Model 2, the level of statistical significance of the model's F statistic increases by $>.0005$, providing a basis for more confidence in the results. In hypothesis testing terms, if an analyst tested the null hypothesis that adding internal value as a predictor variable to the market value predictor variable already in Model 1 does not significantly increase the predictive power of the regression analysis, and then decided to reject that null hypothesis based upon these results, the probability of the analyst being wrong (and making a Type 1 error) would be $<.0005$, or $.05 \%$. Essentially, the results indicate that the market rates and internal values of employees' jobs, together, have a significantly stronger impact on the organization's decisions regarding their pay competitiveness than do market values alone.

Finally, when the market value, internal value, and overall value of employees' jobs are included as predictors of their pay competitiveness in Model 3, the level of statistical significance of the model's $\mathrm{F}$ statistic increases by .007 , providing a basis for yet more confidence in the results. In hypothesis testing terms, if an analyst were testing the null hypothesis that adding overall value as a predictor variable to the predictor variables of market and internal value already in Model 2 does not significantly increase the predictive power of the regression analysis, and then decided to reject that null hypothesis based upon these results, the probability of the analyst being wrong (and making a Type 1 error) would be .007 , or $.7 \%$. Essentially, the results indicate that the market rates, internal values and overall values of employees' jobs, together, had a significantly stronger impact on the organization's decisions regarding their pay competitiveness than did market values and internal values alone.

\subsection{Accuracy of Predictions}

The statistical significance of the regression models' predictions notwithstanding, an important corollary issue is the accuracy of those predictions. Evidence of the differences in the models' prediction accuracy is also included in Table 3. This table shows the value of $\mathrm{R}^{2}$ (i.e., coefficient of determination) for each model included in the partial F test; and indicates that, with each increase in the number of predictor variables in the regression model, the value of $\mathrm{R}^{2}$ increases. In Model 1, when only the market values of jobs are included as a predictor variable, $\mathrm{R}^{2}$ equals .059 indicating that only $5.9 \%$ of the variance in employees' pay competitiveness can be predicted, or explained, by the variance in their jobs' market values (Gravetter, \& Wallnau, 2013). In Model 2, when both the market and internal values of jobs are included as predictor variables, $\mathrm{R}^{2}$ equals .338 indicating that $33.8 \%$ of the variance in employees' pay can be predicted, or explained, by the variance in their jobs' market and internal values. And in Model 3, when the market, internal, and overall values of jobs are included as predictor variables, $\mathrm{R}^{2}$ equals .394 indicating that $39.4 \%$ of the variance in employees' pay can be predicted, or explained, by the variance in their jobs' market, internal and overall values. Additional information on the regression models' prediction accuracy is included in Table 4: 
Table 4. Extra Sum of Squares

\begin{tabular}{|c|c|c|c|c|c|}
\hline Model & $\begin{array}{l}\text { Predictor } \\
\text { Variable(s) }\end{array}$ & $\begin{array}{l}\text { Sum of } \\
\text { Squares } \\
\text { Error }^{1}\end{array}$ & $\begin{array}{l}\text { Reduction in } \\
\text { Sum of } \\
\text { Squares } \\
\text { Error } \\
\end{array}$ & $\begin{array}{l}\text { Sum of } \\
\text { Squares } \\
\text { Regression }^{2}\end{array}$ & $\begin{array}{l}\text { Increase in Sum } \\
\text { of Squares } \\
\text { Regression }\end{array}$ \\
\hline Partial Model 1 & Market Value & 1.295 & $\mathrm{n} / \mathrm{a}$ & 0.081 & $\mathrm{n} / \mathrm{a}$ \\
\hline Partial Model 2 & $\begin{array}{l}\text { Market Value } \\
\text { Internal Value }\end{array}$ & 0.910 & $-30 \%$ & 0.465 & $474 \%$ \\
\hline Full Model 3 & $\begin{array}{l}\text { Market Value, } \\
\text { Internal Value, } \\
\text { Overall Value }\end{array}$ & 0.834 & $-8 \%$ & 0.542 & $17 \%$ \\
\hline
\end{tabular}

${ }^{1}$ In regression analyses, Sum of Squares Error equals the sum of the squared differences between the actual values $(\mathrm{Y})$ and predicted values $(\hat{\mathrm{Y}})$ of a variable (i.e. $\mathrm{SSE}=[\Sigma(\mathrm{Y}-\hat{\mathrm{Y}}) 2]$. In this analysis, the variables of interest are the predictor variables included in each model, and Sum of Squares Error reflects the error or inaccuracy in predicting the values of these variables. The smaller the value, the less inaccuracy there is.

${ }^{2}$ In regression analyses, Sum of Squares Regression equals the sum of the squared differences between the predicted values $(\hat{Y})$ and average actual value $(\bar{y})$ of a variable (i.e SSR $=[\Sigma(\hat{Y}-\bar{y}) 2]$. In this analysis, the variables of interest are the predictor variables included in each model, and Sum of Squares Regression reflects the accuracy in predicting the values of these variables. The larger the value, the more accuracy there is.

As discussed above, the differences between employees' actual pay competitiveness and the pay competitiveness predicted by a regression model reflect the model's prediction error. Statistically, this error represents the model's Sum of Squares Error (SSE) or the sum of the squared differences between the actual values (Y) and predicted values $(\hat{Y})$ of pay competitiveness (i.e., SSE $=\left[\Sigma(\mathrm{Y}-\hat{\mathrm{Y}})^{2}\right]$ : the smaller the value of SSE, the more accurate the regression model's. predictions are. The data in Table 4 show what Kutner, Nachtsheim, \& Neter (2004) refer to as Extra Sum of Squares or the marginal changes in the values of SSE with each additional predictor variable added to a model. These data indicate that the value SSE is highest in Model 1 when the influence of only the market value of employees' jobs is evaluated. The value of SSE is substantially lower in Model 2 when the influence of the market and internal values of employees' jobs is evaluated, and the value of SSE is lowest in Model 3 when the influence of the market, internal, and overall value of employees' jobs is evaluated.

As the error in predicting pay competitiveness decreases, there is a corresponding increase in the agreement between the model's predictions and employees' actual pay competitiveness Statistically, this agreement is measured by the value of Sum of Squares Regression (SSR) or the sum of the squared differences between the predicted values $(\hat{Y})$ and average actual value $(\bar{y})$ of pay competitiveness. (i.e., SSR $=\left[\Sigma(\hat{Y}-\bar{y})^{2}\right]$ : the larger the value of SSR, the more accurate the regression model's predictions are. The data in Table 4 indicate that the value of 
SSR is lowest in Model 1 when the influence of only the market value of employees' jobs is evaluated. The value of SSR is substantially higher in Model 2 when the influence of the market and internal values of employees' jobs are evaluated, and the value of SSR is highest in Model 4 when the influence of the market, internal, and overall value of employees' jobs is evaluated.

\section{Discussion}

The results of the analysis indicate that market values, internal values, and overall values of employees' jobs each account for a significant portion of the variance in employees' pay competitiveness and, by implication, the organization's decision-making regarding their pay competitiveness. However, the above notwithstanding, these results address a number of key issues regarding the relative influence of market, internal, and overall job value in making pay decisions.

\subsection{Relative Influence of Market Rates}

The importance of market data to attracting, retaining, and motivating employees means that most organizations must consider it to remain viable entities. The author is reminded of a nonprofit organization that was strongly dedicated to its mission of serving others and developed a culture that fostered this dedication by recognizing the necessary contribution made by each job in the organization (i.e., by recognizing the job's internal value). Ultimately, its growth required that it systemically address the market values of employees' jobs in making pay decisions. After repeated efforts to avoid confronting the issue, the CEO finally "set the table" for its discussion by reminding his senior staff that, "like it or not, this is the world we compete in". Hence, even organizations that strongly prefer to do otherwise, recognize the importance of jobs' market rates in compensation decision-making. However, this recognition is often assumed to indicate the willingness of organizations to weigh the market values of jobs more heavily than other components of job value (Romanoff, Boehm, \& Benson, 1986). These results indicate this may not be the case. While market value is a significant predictor of employees' pay competitiveness, both the partial $\mathrm{F}$ test and analysis of Extra Sum of Squares indicate that its relative power to explain the variance in pay competitiveness is weak compared to the combined power of both market and internal value, and weaker still when overall value is added as a third predictor. Consequently, while these results support the importance of market data in making pay decisions, they call into question the weight organizations assign these data, alone, in their decision-making process.

\subsection{Relative Influence of Internal Value}

As a corollary of the recognition typically given the market value of jobs in compensation planning, internal job value is often regarded as secondary to organizations' need to compete effectively in the appropriate labor markets (Romanoff, Boehm, \& Benson, 1986). However, the results of both the partial F test and analysis of Extra Sum of Squares indicate that, when the definition of internal value is tailored to the organization's definition, and effectively discriminates among the internal values of the organization's jobs, internal job value dramatically increases the amount of explained variance in employees' pay competitiveness. 


\section{Ml Macrothink}

International Journal of Human Resource Studies

ISSN 2162-3058

2019, Vol. 9, No. 1

Whether or not more generic definitions of internal value have the same impact remains an issue for future research.

\subsection{Relative Influence of Overall Job Value}

The overall value trendline, or regression line, is based upon the predicted market rates of jobs given their internal value to the organization. The more accurate the trendline's prediction of market rates, the stronger the correlation between the jobs' actual and predicted market rates becomes. Under these conditions, it might be assumed that the trendline is simply a tool for estimation of the market value of jobs without any additional value for compensation planning. However, both the partial $F$ test and Extra Sum of Squares analysis done here indicate that overall job value, per se, explains a significant amount of the variance in employees' pay competitiveness in addition to the variance explained by the market and internal values of jobs. This additional significance reflects, not only the correlation, or agreement, between predicted and actual market rates, but also the degree to which these values differ (Liccione, 1992). Indeed, from an overall value perspective, the latter provides important information on the influence of jobs' internal values which may be taken into account when making pay decisions.

To illustrate the potential role of overall value in compensation planning, the information on the Overall Value Trendline in Figure 1 indicates the correlation between the market values and overall values of the 41 jobs represented is a strong .89; while the information on the database used in this analysis in Table 2 indicates the average difference between the market values and overall values of jobs is only $\$ 109$. Yet, despite this evidence of strong agreement between these two measures, Table 2 also tells us there remains an average deviation, or fluctuation, between overall job values and market rates of $\$ 5,117$. As a result, the overall value of a job to the organization may, on average, be $\$ 5,117$ above its market value and provide a rationale for paying a premium over market, or $\$ 5,117$ below its market value, and provide a rationale for paying a discount off the job's market rate. It is this holistic assessment of jobs based upon the impact of jobs' internal values on their market values that distinguishes overall value from either market value or internal value, alone, as predictors of employees' pay competitiveness.

\section{Conclusion}

These data underscore at least three key points. First, although organizations' willingness to pay fully competitive market rates for their jobs (i.e., the jobs' $50^{\text {th }}$ percentile market rates) is certainly an important determinant of their ability to initially attract and retain employees, market rates, alone, have relatively little impact on the organizations' decision to offer employees' compensation in excess of this benchmark. In fact, market rates, alone, explain less than $6 \%$ of the variance in employees' pay competitiveness and are not a statistically significant predictor of that pay competitiveness.

Second, when organizations consider both the market and internal values of jobs, these values, together, have a significantly stronger impact on decisions regarding pay competitiveness than market values alone. And, when the overall values of jobs are "added to the mix" these 
three factors indicate the strongest impact on pay competitiveness. This last finding suggests that overall job value, per se, is not simply a restatement of the additive influence of jobs' market and internal values, but rather a distinct, third type of job value that defines the impact of jobs' internal values on their market values.

And third, the more central to decisions regarding pay competitiveness the internal values of jobs are, the more impact on pay competitiveness these decisions have. Hence, these data suggest that organizations rely relatively heavily on the internal values of their jobs in making pay decisions and, ipso facto, their ability to objectively and reliably measure those internal values.

\section{Acknowledgement}

This study was supported by Compensation Planning \& Analytics.

\section{References}

Adams, J. S. (1963). Toward an Understanding of Inequity. Journal of Abnormal and Social Psychology, 47, 422-436. https://doi.org/10.1037/h0040968

Adams, J. S. (1965). Inequity in Social Exchange, In K. Berkowitz (Ed.) Advances in Experimental Social Psychology, 2, New York: Academic Press. https://doi.org/10.1016/S0065-2601(08)60108-2

Dielman, T. E. (2005). Applied Regression Analysis: A Second Course in Business and Economic Statistics (4th ed.). Mason, OH: South-Western Cengage Learning. 91-96.

Gravetter, F. J., \& Wallnau, L. B. (2013). Statistics for the Behavioral Sciences (9th ed.). Belmont, CA: Wadsworth Cengage Learning. 524.

Kutner, M. H., Nachtsheim, C. J., \& Neter, J. (2004). Applied Linear Regression Models (4th ed.) New York, NY: McGraw-Hill. 256 - 262, 283 - 284.

Liccione, W. J. (1992). JobValue: A Measure of Overall Job Worth, Compensation \& Benefits Management, 8(2), 45-49. https://doi.org/10.1177/0886368714545931

Liccione, W. J. (2014) Linking the Market and Internal Value of Jobs: Rethinking the Market Line, Compensation \& Benefits Review, 46(2), 80-88.

Martocchio, J. J. (2011). Strategic Compensation: A Human Resource Management Approach (6th ed.). Upper Saddle River, NJ: Prentice Hall. 167.

Newman, J. M., Gerhart, B., \& Milkovich, G. T. (2017) Compensation (12th ed.). New York, NY: McGraw-Hill. $286-291$.

Romanoff, K., Boehm, K., \& Benson, E. (1986). Pay Equity: Internal and External Considerations, Compensation \& Benefits Review, 18(6), 17-25. https://doi.org/10.1177/088636878601800602

Stecher, M. D., \& Rosse, J. G. (2007). Understanding Reactions to Workplace Injustice Through Process Theories of Motivation: A Teaching Module and Simulation. Journal of 
Management Education, 31(6), 777-796. https://doi.org/10.1177/1052562906293504

Tyler, T. R., Rasinski, K., \& McGraw, K. (1985). The influence of perceived injustice on the endorsement of political leaders. Journal of Applied Social Psychology, 15, 700-725. https://doi.org/10.1111/j.1559-1816.1985.tb02269.x

\section{Copyright Disclaimer}

Copyright for this article is retained by the author(s), with first publication rights granted to the journal.

This is an open-access article distributed under the terms and conditions of the Creative Commons Attribution license (http://creativecommons.org/licenses/by/4.0/). 